\title{
Speed, Stability and Maintenance of New and Reusable Computer to the User: A Comparative Study
}

\author{
Norazli Othman, Samira Albati Kamaruddin, Nor'azizi Othman, and Abdul Moeis Abdul Shukor
}

\begin{abstract}
Approach towards environmental friendly development concept introduces green technology computing system (GTCS) as a technique to reuse obsolete computer in sustainable manner. Instead of purchasing new computers to replace old computers, the disc on Module (DOM) can be installed into the obsolete computer to transform them into GTCS. In this study, the obsolete computers with GTCS were tested to run all the software programs that were usually utilized in the new computers. The survey questionnaires methodology is established to support the result of the computer data processor in terms of speed, stability and maintenance of the new and obsolete computer to the user. The result of the study shows that, obsolete computer shows the best performance to the users in terms of speed, stability and maintenance. However, new computer shows the best stability in terms of computer graphic condition and computer accessory condition. The finding of the study reveals that GTCS can contribute to reduce computer waste volume due to the reuse of obsolete computers by the users. This green solution is environmental friendly solution for managing computer waste in future
\end{abstract}

Index Terms-Green technology computing system, performance, reusable computer.

\section{INTRODUCTION}

The industrial revolution and over helming development of information technology have changed the present society's lifestyles. To date, the society has become dependable on the usage of electronic product such as computer, telephones, washing machine and others. An electronic waste refers to the expiration of a product's life span and that includes computers, printers, photocopy machines, televisions, hand phones and toys made from mixtures of plastics, metals and other materials [1]. Information technology and telecommunications equipment seems to be the dominant of waste electric and electronic being generated in terms of number especially in Africa, in the poorer region of Asia and in South America [2]. The largest component of the electronic waste stream is computer monitor [3]. Basically computers monitors contain cathode ray tubes (CRTs). If the CRTs being incinerates or landfill, the lead in CRTs will be released to the environment. The emission of lead will potentially give health effects and associate damage to the

Manuscript received June 25, 2014, revised October 30, 2014. This work was supported in part by the Malaysian Ministry of Higher Education under Research University Grant Scheme. Speed, Stability and Maintenance of New and Reusable Computer to the User: A Comparative Study.

Norazli Othman, Samira Albati Kamaruddin, and Nor'azizi Othman are with the Universiti Teknologi Malaysia, Kuala Lumpur, Malaysia (e-mail: norazli@ic.utm.my, samira@ic.utm.my, azizi@ic.utm.my).

Abdul Moeis Abdul Shukor is with the Ministry of Education, Putrajaya, Malaysia (e-mail: moeis1973@gmail.com). human being and the environment [3].

In general, electronic wastes including computer waste comprise more than 1000 diverse components in which most of the components contain high toxic compounds that are able to pollute the environment [4]. The toxic constituents are heavy metal (cadmium, chromium, mercury, lead, arsenic etc.) organic chemical compounds i.e. Poly Chloro Biphenyls and flame retardant including plastic resins Polyvinyl Chloride [5]. From the aspect of health, heavy metals like cadmium may have an effect on the functions of kidneys and liver including to reduce mineralization process and to lessen the calcium substance in bones. A long-term exposure to cadmium may risk oneself to cancers and a disease known as itai-itai. Another metal like chromium may lead to lungs cancer, kidneys failure and also breathing problems. The existence of heavy metal like mercury is able to disfigure the functions of the brain.

Flame retardant that consists of constituents like chlorine, phosphorus, nitrogen, and bromine contributes to environmental problems due to its toxic characteristics and ability to produce bio-particles. A scientific study also shows that the compound may increase the risks for cancer and cause toxic neutron effects [6].

The pattern of computing technology nowadays are it will be upgraded and revised day by day in order to adapt with communities demand and as a tool for organizing an effective marketing strategy. However, every time the version is upgraded, there is a need of a new specification of the Central Processing Unit (CPU) of the computers. Usually latest version required more Random Access Memory (RAM) compared to the earliest version. Basically, the performance of the computer will be directly affected by the capability of the Central Processing Unit (CPU), Graphic Processing Unit (GPU) and the amount of Random Access Memory (RAM) available on the computer. The types of software and the internet content accessed will also affect the system's performance.

The updated version of the computer software contributes to the various developing technology such as Fat Client Networks technology, Thin Client Network technology and other computing technology. The technologies formulate technique to move together with the updated version of computer software [7]. The formulated technologies contribute to the reduction of the total computer waste volume.

Basically, the waste management strategies highlighted that the most effective management technology is by reducing the accumulation wastes. Therefore, the waste reduction technology is on the highest stage of the system followed by the recycling and recovery and the final solution is disposal solution [8]. In line with the waste management 
strategies, reuse of obsolete computers is essential in reducing the number of computer waste. To realize the current approach towards environmental-friendly development concept, green technology computing system (GTCS) as a technique for the reuse of obsolete computers in sustainable manner is introduced in this study. Basically, computing system that user friendly reflect the overall performance of the computer. The performance such as the speed, stability and the maintenance task of the computers is the main factors that give satisfaction to the user. For that reason, the objective of this paper is to compare and evaluate the performance of the obsolete computer and new computer to the users in terms of its speed, stability and maintenance aspect.

\section{Methodology}

The methodology for this study is divided into two i.e. model development for obsolete computer with GTCS and survey study about the performance, stability and maintenance of the new and obsolete computer to the computer user.

For new computer, the model is a unit of new computer. For reusable computers, the model development involves the development of green technology computing system (GTCS). The objective of developing the GTCS is to increase the performance of obsolete computer. The set up of GTCS includes networking development, disc on module (DOM) installation and computer programmed installation. The GTCS has a total of ten obsolete computers, a server, a port switch, a router and networking system. The specification of the obsolete computer is Pentium 3 with $64 \mathrm{MB}$ random access memory and the date of purchase is at year 2002. Fig. 1 shows the model development of GTCS.

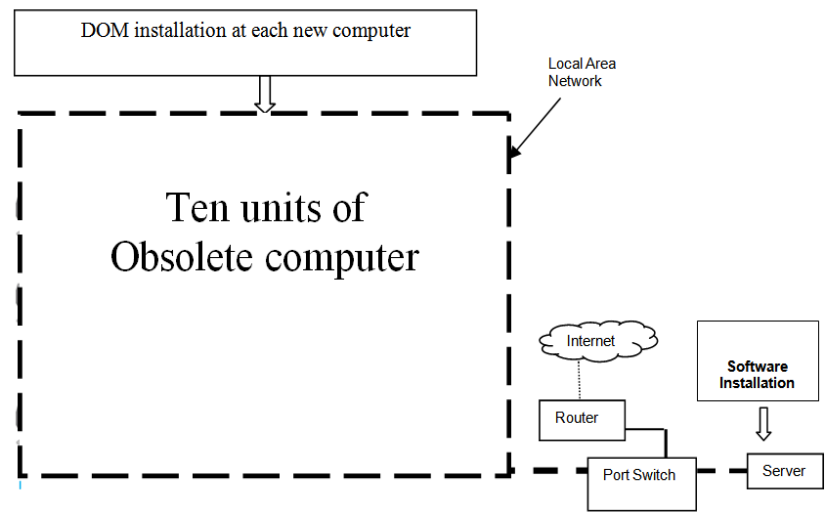

Fig. 1. Model development of obsolete computer with green technology computing system [9].

For GTCS, all of the obsolete computer will be running at the server. No hard disc is required for each obsolete computer. The server will act as a central processing unit for all computers. Programmed software's are installed at the server. The DOM with $512 \mathrm{MB}$ random access memory is installed into each of the obsolete computers. The maintenances of the obsolete computer are operated at the system server. The survey questionnaires methodology is established to support the result of the computer data processor in terms of speed, stability and maintenance. The survey questionnaire is distributed to thirty users to evaluate the speed and the stability of the new and reusable computer. The maintenance aspect of new and obsolete computers to the users is measured through the feedback survey from the computer technician. There will be thirty survey questionnaires distributed to the computer technician to evaluate the maintenance aspect of the computing system.

\section{RESULT}

Fig. 2 to Fig. 19 tabulate the result of the overall study. Based on the survey results, in average about $98 \%$ of the users agree that there is no problem to turn on and to turn off the new and obsolete computers (Fig. 2). With refer to Fig. 3, in average about $5 \%$ of the users agree that obsolete computer give problem when the user want to open the computer programmed while about $11 \%$ of the user agree that new computer give problem to the user when the user try to open the same programmed. With refer to Fig. 4, in average about $8 \%$ of the users agree that new and obsolete computer give problem when the users want to use the computer programmed.

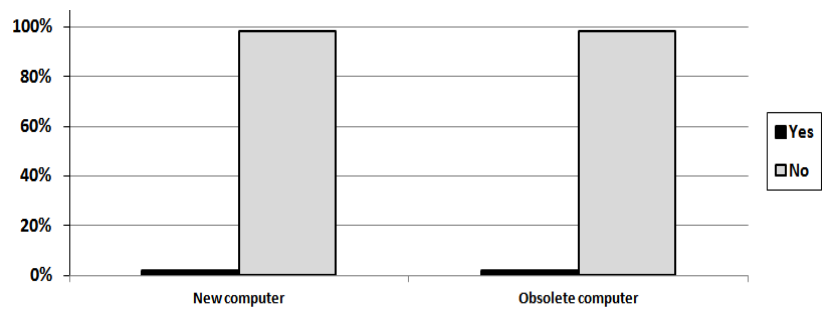

Fig. 2. Problem to turn on and turn off computer.

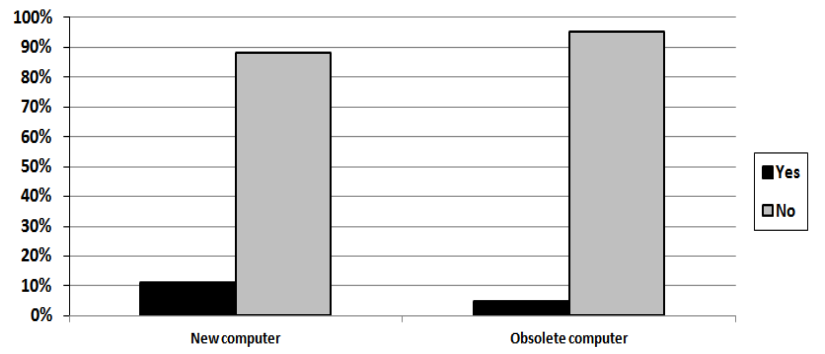

Fig. 3. Problem to open computer programmed

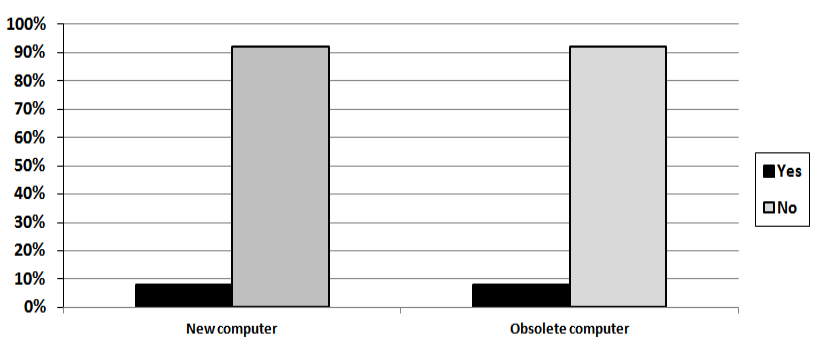

Fig. 4. Problem to use computer programmed.

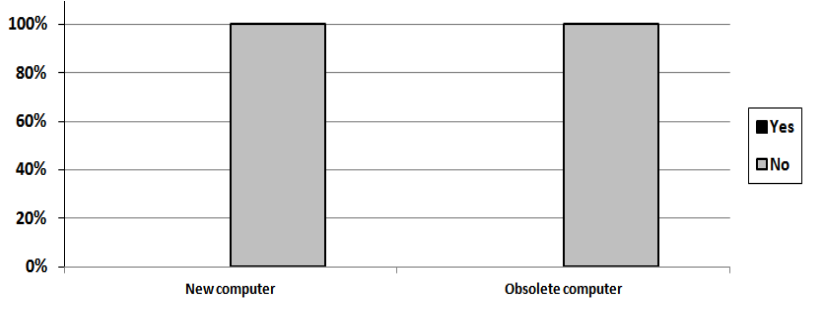

Fig. 5. Problem to save file for each computer programmed.

To refer to Fig. 5, the survey result shows that all of the 
users strongly agree that there is no problem to save programmed file for new and obsolete computers. With refer to Fig. 6, in average about $3 \%$ of the users agree that obsolete computer give problem when the user want to download file for each computer programmed while about $6 \%$ of the user agree that new computer give problem to the user when the user try to download file for the same programmed.

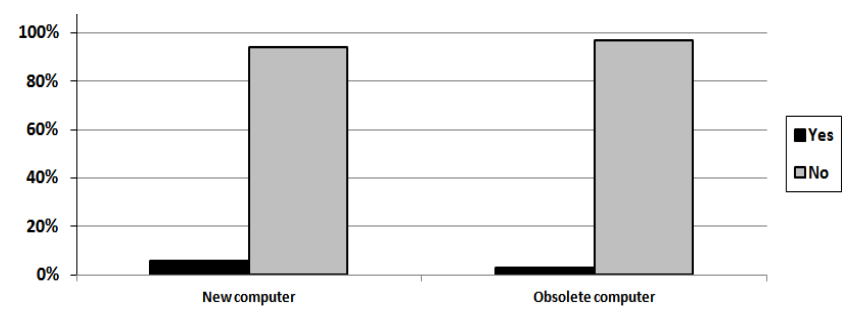

Fig. 6. Problem to download any file for each computer programmed.

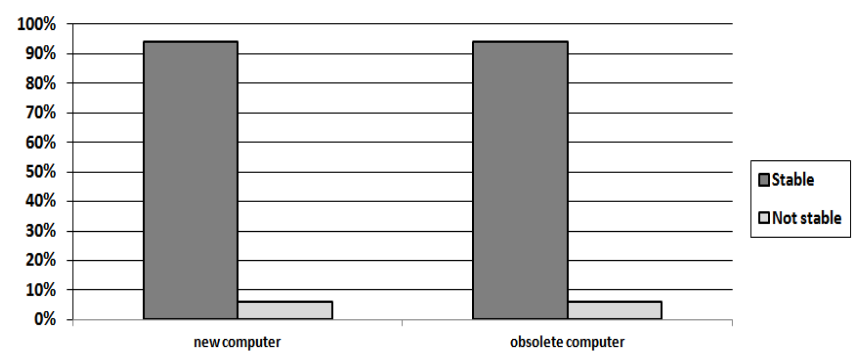

Fig. 7. Computer system disorder such as delayed or stop when using the computer.

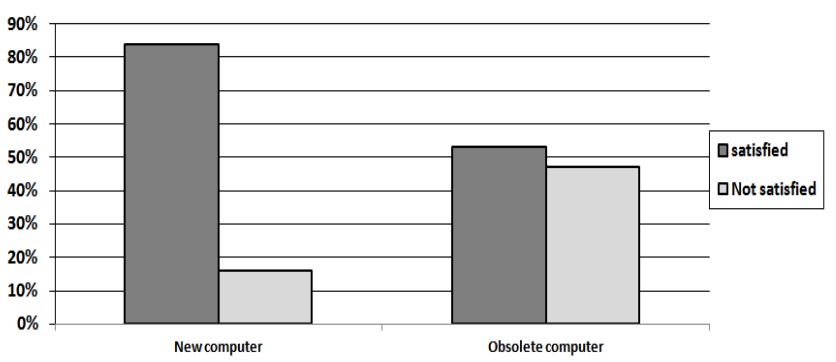

Fig. 8. Stability in terms of computer graphic condition.

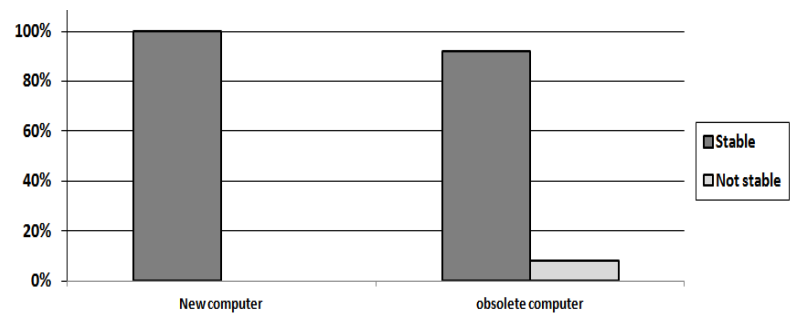

Fig. 9. Stability in terms of computer accessory.

Survey result in Fig. 7 shows that in average about $92 \%$ of the users agree that the new and obsolete computers seldom have computer system disorder such as delayed or stop when using the computers. The survey result also shown that about $84 \%$ of the user satisfied with the computer graphic condition of new computer while about $50 \%$ of the users satisfied with the computer graphic condition of obsolete computer as stated in Fig. 8. With refer to Fig. 9, the survey result shows that $100 \%$ users satisfied with new computer accessory such as CD-ROM, drive, scanner, printer, thumb drive and others while only $92 \%$ of the user satisfied with the obsolete computer accessory. In summary, the survey results revealed that the new computer shows the best stability in terms of computer graphic condition and computer accessory condition. However, obsolete computer shows the best stability when the computer programmed software is used.

Fig. 10 to Fig. 14 tabulate the survey results about the speed while using the computer. In general, the speed of the computer indirectly influences the performance of the computer to the user. In comparison between obsolete and new computer, about $82 \%$ of the users agree that obsolete computer shows the fastest speed when turning the computer on and about $47 \%$ of the users agree that new computer shows the fastest speed when turning the computer on (Fig. 10). In refer to Fig. 11 and Fig. 12, about $82 \%$ of the users agree that obsolete computers shows the fastest speed when open and running variety of computer programmed while about $52 \%$ of the users agree that new computer shows the fastest speed when open and running variety of computer programmed.

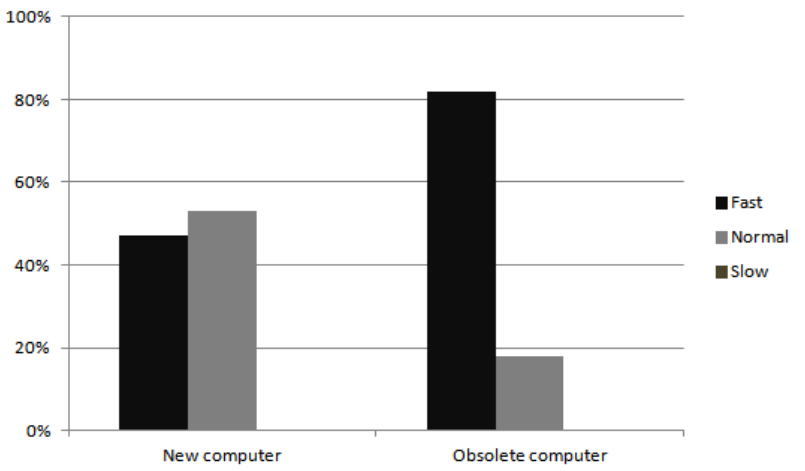

Fig. 10. Length of time to turn on computer.

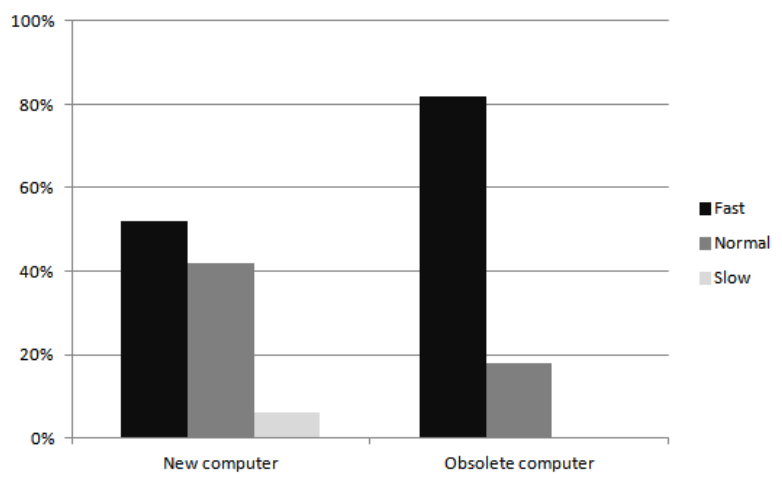

Fig. 11. Length of time to open the computer programmed.

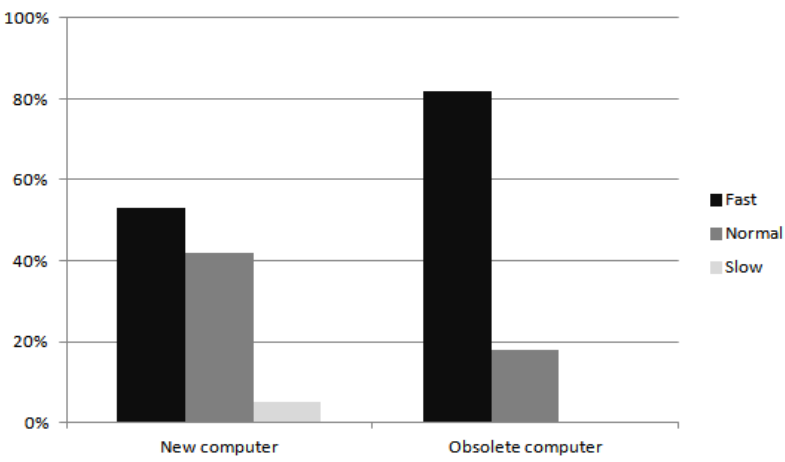

Fig. 12. Speed while using variety of computer programmed.

Plotted data in Fig. 13 shows that about $94 \%$ of the users agree that obsolete computer shows the fastest speed when saving files for variety of computer programmed compared to only $63 \%$ of the user agree that new computer shows the fastest speed when saving files for variety of computer programmed. The feedback from the user about the 
performance in terms of speed when download any file for variety of computer programmed shows that $76 \%$ of the user agree that obsolete computers shows the best performance compared to only $63 \%$ of the users agree that new computer shows the best performance (Fig. 14). This feedback from the users indicates that obsolete computer shows the best performance to the users in terms of speed when using the computer.

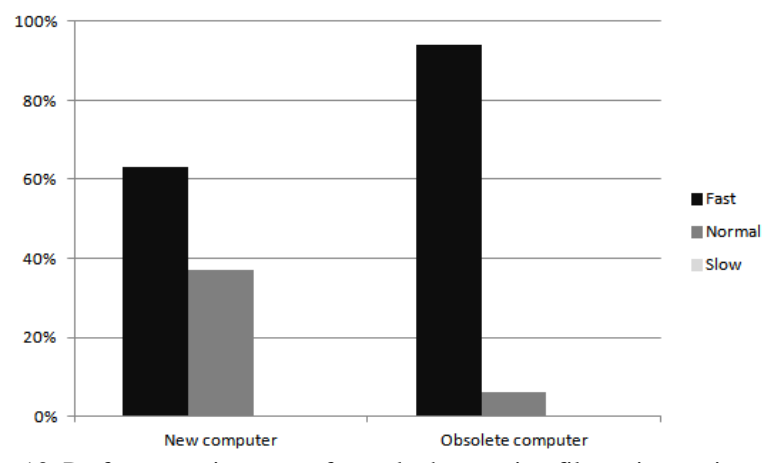

Fig. 13. Performance in terms of speed when saving files using variety of computer programmed.

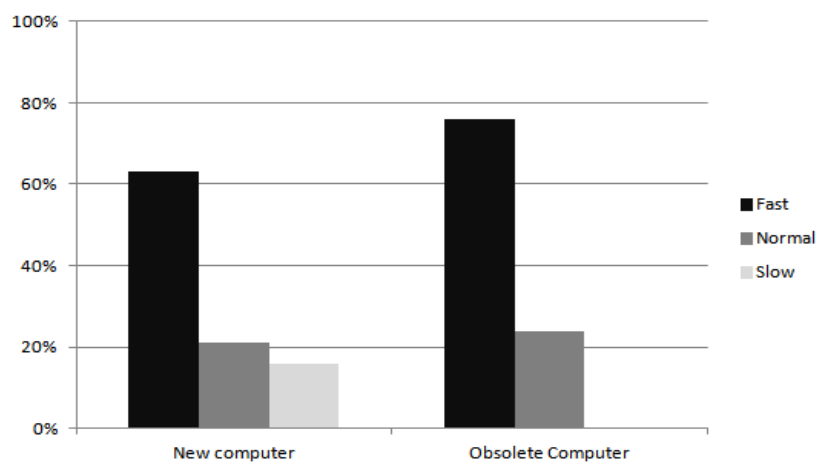

Fig. 14. Performance in terms of speed when download any file for variety of computer programmed.

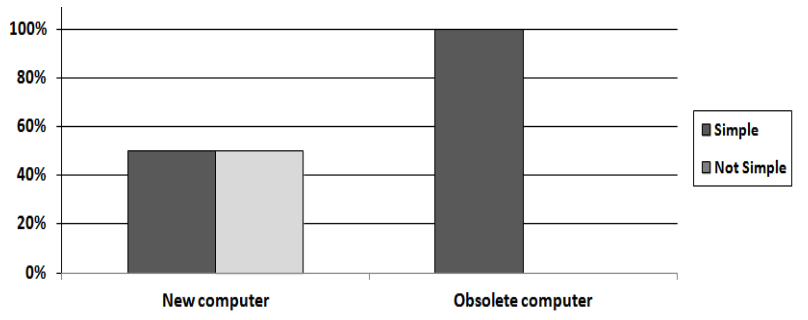

Fig. 15. Network management i.e installation and security.

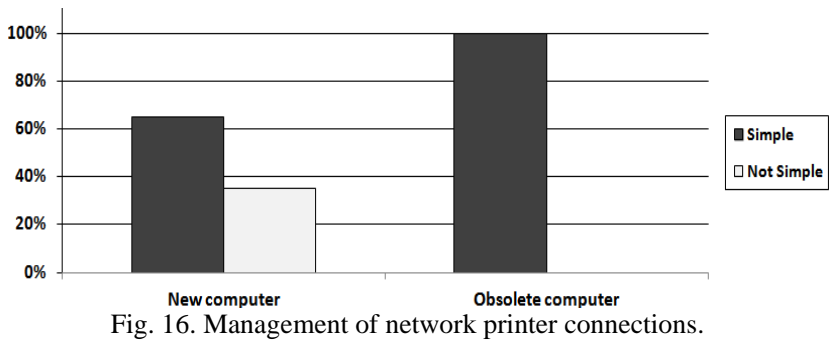

Fig. 15 until Fig. 19 shows the survey result of computer maintenance work. Based on the survey results, $100 \%$ of the respondent agree that obsolete computers with GTCS makes maintenance work such as network management, management of network printer connections, configuration of the server, controlling installation at the computer application an easiest task. The respondent also agreed that computer maintenance for obsolete computer can be done in a short time. In conclusion, the survey result revealed that obsolete computer with GTCS shows the simplest way to maintain the computer compared to the new computer.

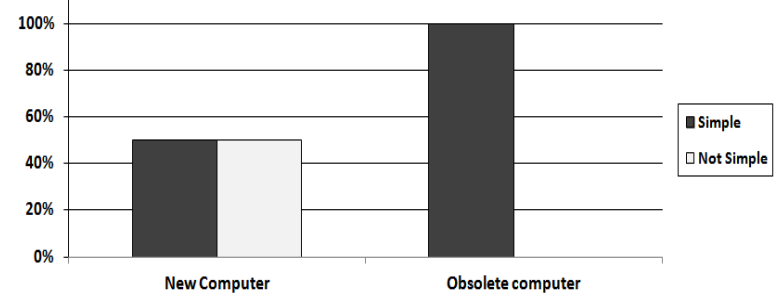

Fig. 17. Configuration of the server.

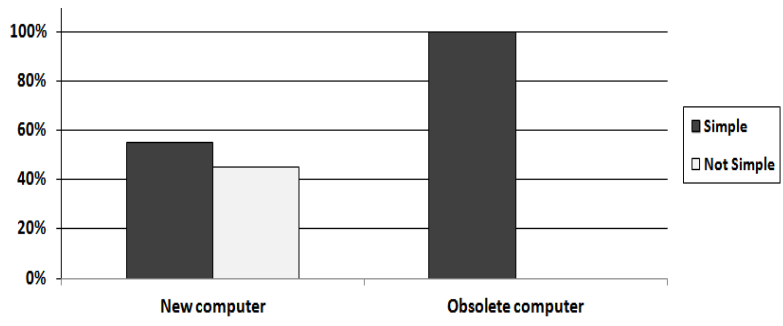

Fig. 18. Controlling the installation at the computer application.

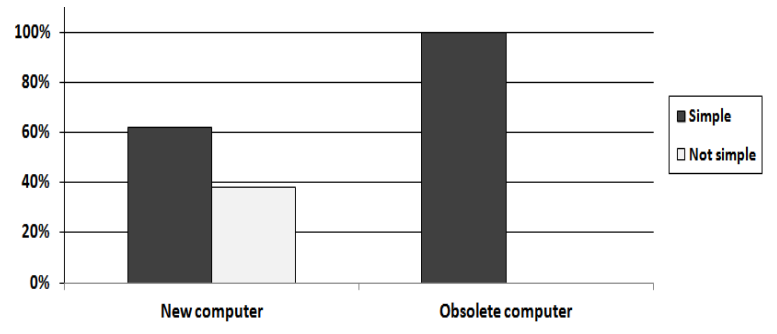

Fig. 19. Maintenance work on a limited time.

\section{DISCUSSION}

From the survey results, the majority of the respondent could not find any different between the obsolete computers and new computers. The software programmed performed very well during the survey study for both new and obsolete computer. Almost all of the computer application could be run smoothly for both new and obsolete computer systems. However, obsolete computer shows a little unsatisfied graphic condition but overall the performance was still acceptable. The feedback from the respondent i.e. technician commented that obsolete computer with GTCS is easy to maintain compared to normal personal computer systems. The technician commented that, if issues such as computer system hang, blue screen or spyware happened, they was able to login an administrator to perform recovery at the terminal server. In addition, all of the installation programmed or the 'save file' by users to the computer is done at the same server This makes it much more easier and time saving to do maintenance and to do housekeeping to the computer system.

Basically, there are no more maintenance tasks such as reformatting of hard disc drives, restoring of operating system, scanning and cleaning the viruses, and housekeeping on the computer as individual basis for obsolete computer with GTCS. The GTCS allows the technician to perform the maintenance task for all computers at the server. In addition, maintaining the terminal server is relatively easy based on a well-defined group policy and user privilege. Unauthorized user cannot change the system configuration such as 
wallpaper setting or install any software into the system. The system administrator only has the right to install or uninstall any necessary software. However, reuse of the computer is discouraged if there is an issue with the motherboard, memory, graphics or power supply.

The advantages for reusing of the obsolete computer are the minimization of computer waste, expanding computer lifespan, expanding landfill site lifespan, reduce technician workload for computer maintenance and reduce cost for maintenance and upgrade computers. The disadvantages of reusing the obsolete computer are the lack of performance for computer graphic, obsolete computer has no esthetic value to the user and obsolete computer unable to run heavy programmed such as AutoCAD. Due to the advantages and disadvantages of reusing obsolete computer, it is recommended to reuse the obsolete computer at non-profit organization such as the school access centre, internet cafe, library and schools.

\section{CONCLUSION}

Computer waste management should be integrated with the computing technology in order to manage the increase of computer waste generated. This green technology solution for computer waste management will enhance the sustainability in terms of environment and economic manner in future.

\section{ACKNOWLEDGMENT}

The writer wishes to express her greatest appreciation and utmost gratitude to the Ministry of Higher Education (MOHE), Universiti Teknologi Malaysia (UTM) and Ministry of Education for all supports in making the study a success.

\section{REFERENCES}

[1] M. H. Wong, S. C. Wu, W. J. Deng, X. Z. Yu, Q. Luo, A. O. W. Leung, C. S. C. Wong, W. J. Luksemburg, and A. S. Wong, "Export of toxic chemicals-A review of the case of uncontrolled electronic waste recycling," Environmental Pollution, Elsevier, pp. 131-140, 2007.

[2] F. O. Ongondo, I. D. Williams, and T. J. Cherrett, "How are WEEE doing? A global review of the management of electrical and electronic wastes," Journal of Waste Management, Elsevier, pp 714-730, 2011.

[3] M. Macauley, K. Palmer, and J. Shin, "Dealing with electronic waste: Modeling the costs and environment benefits of computer monitor disposal," Journal of Environmental Management, Elsevier, pp. 13-22, 2003.

[4] R. Widmer, H. O. Krapf, D. S. Khetriwal, M. Schnellmann, and H. Boni, "Global Perspectives on E-waste," Environmental Impact Assessment Review, Elsevier, pp. 436-458, 2005.

[5] T. G. Townsend and K. Vann, "Leaching of Hazardous Chemicals from Discarded Electronics," presented at National Electronic Equipment Management and Compliance Assistance Workshop Atlanta, 2002.
[6] T. V. Ramachandra and V. K. Saira, "Environmentally Sound Options for E-waste Management," Envis Journal of Human Settlements, 2004

[7] A. B. Batto, Thin Client Computing Installation Manual, The Center of Information and Communication Technology for development Bolivia and world computer exchange of North America, 2007.

[8] M. Saib, "Solid Waste Management in Malaysia- The Way Forward," in Proc. $5^{\text {th }}$ Asian Symposium on Academic Activities for Waste Management, Kuala Lumpur, 2002.

[9] N. Othman, S. Chelliapan, N. A. Othman, A. M. A. Shukor, and S. A Kamaruddin, "New Computer and Reuse of Obsolete Computer: A comparative Performance," International Proceedings of Economics Development and Research, vol. 66, pp. 1-6, 2013.

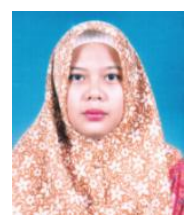

Norazlibinti Othman graduate from University of Science Malaysia in 1997. She received doctor of philosophy degree from the National University of Malaysia in 2009. She is currently a senior lecturer at University of Technology, Malaysia. Her specialization is in environmental management, solid waste management, life cycle assessment, water engineering and wastewate engineering. She has more than 15 years of academic experience and also has working experience as an engineer, consultant and researcher. She has presented her research in local and international conferences and published in many proceedings, book of chapters and journals. Her research interest is in electronic waste management and life cycle analysis.

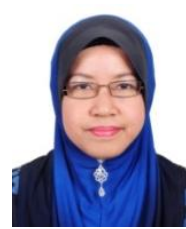

Samira Albati Kamaruddin graduate from University Technology of Malaysia in 1998. She received doctor degree of philosophy from University of Putra Malaysia in 2013. She is currently a senior lecturer at University of Technology, Malaysia. Her specialization is in environmental hydrology and hydrogeology. Currently, she is the head of Civil Engineering Panel. She is the member of Climate Change Research Group in water research alliance. She currently supervises a few master and doctoral research students specializing in hydrology and water resources projects, as well as other civil engineering disciplines. Her research interests are in soil and groundwater contamination, groundwater remediation, image analysis technique and waste management.

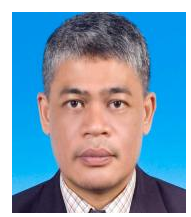

Nor'azizi Othman graduate from Seoul National University, Korea in 1993. He received doctor degree of engineering from Kyushu University of Japan in 2013. He is currently a senior lecturer at University of Technology, Malaysia. He has more than 20 years' academic experience and also has working experience as an engineer and researcher. His specialization is in biomass and biochar gasification. His research interests are in environmental pollution, activated carbon and renewable energy.

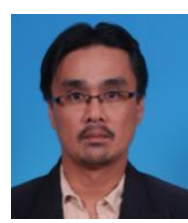

Abdul Moeis Abdul Shukor graduate from Open University Malaysia in 2011. He has diploma degree in network technology from Informatics College in 2000 $\mathrm{He}$ is currently an education technology officer at Ministry of Education, Malaysia. He has more than 10 years' academic experience and also has working experience as a researcher. His specialization is in network technology and information technology. His research interests are in computing technology. 